\title{
A Commentary: Herbal Medicine Offers Great Potential in Support of Metronomic Cancer Therapy
}

\author{
Clara Bik-San Lau ${ }^{1,2}$, Chun-Kwok Wong1,2,3, Ping-Chung Leung, ${ }^{1,2,4^{*}}$ \\ ${ }^{1}$ Partner State Key Laboratory of Phytochemistry and Plant Resources in West China, The Chinese University of Hong Kong, \\ Hong Kong \\ ${ }^{2}$ Institute of Chinese Medicine, The Chinese University of Hong Kong, Hong Kong \\ ${ }^{3}$ Department of Chemical Pathology, The Chinese University of Hong Kong, Hong Kong \\ ${ }^{4}$ Metronomic Global Health Initiative, Marseille, France \\ Email: *pingcleung@cuhk.edu.hk
}

How to cite this paper: Lau, C.B.-S., Wong, C.-K. and Leung, P.-C. (2017) A Commentary: Herbal Medicine Offers Great Potential in Support of Metronomic Cancer Therapy. Journal of Cancer Therapy, 8, 86-95.

https://doi.org/10.4236/jct.2017.82008

Received: January 9, 2017

Accepted: February 6, 2017

Published: February 9, 2017

Copyright $\odot 2017$ by authors and Scientific Research Publishing Inc. This work is licensed under the Creative Commons Attribution International License (CC BY 4.0).

http://creativecommons.org/licenses/by/4.0/

\begin{abstract}
Background: In spite of the advances in Cancer treatment, limitations exist. Refractory cases and late presentations are particularly worrying. The uncertainty of cure and the high costs have led to the popularly of complementary and alternative medicine in cancer treatment. Herbal medicine has particular attraction because it has been shown to be working on a multi-targets direction: promoting apoptosis of cancer cells, anti-angiogenesis and immuno-modulating. Research on creating a simple herbal formula with multiple effects of cancer control has started and showed in laboratory platforms promising results. Metronomic Chemotherapy: Attention on the use of old oral cytotoxic drugs in small doses for refractory and late cancer cases has started more than a decade. Satisfactory and good results have been found to be related to anti-angiogenesis, immunomodulations and cancer cell apoptosis. These findings are comparable to the use of multiple targets herbal medicine. Conclusion: Assumption is made that metronomic chemotherapy, combined with herbal medicine could be achieving synergistic effects and would be affordable to all patients.
\end{abstract}

\section{Keywords}

Cancer, Metronomic Treatment, Herbal Medicine

\section{Introduction}

Cancer remains one of the most threatening diseases all over the world. Mortalities are steadily rising with the improving longevity of the general population [1] [2] [3] in spite of the scientific advances. The multidisciplinary management: 
surgery, chemotherapy and radiotherapy, has been effectively supported by targeted biological therapies [4]. Sadly, limitations are still plentiful. Late presentations and refractory eases are not uncommon, and the high costs of the therapeutic choices of recent advances could be unaffordable to the less affluent, not to speak about the developing countries [5].

The uncertainty of cure and the threat about recurrences have led to the popular use of Complementary and Alternative Medicine (CAM) [6]. Surveys done in Germany showed that 77\% of cancer patients used CAM [7]. In USA, the incidence is around 50\% [8]. Hong Kong, being a city with mainly Chinese population, has a very high popularity on the use of traditional Chinese medicine, reaching $90 \%$ of the community. Acupuncture has been widely used for pain control arising from different types of cancer. Herbal medicine has been popular for the control of diarrhea, nausea and other types of gastrointestinal problems [9].

\section{Traditional Chinese Medicine for Cancer Patients}

Cancer patients may have specific expectations about the use of CAM, like soothing the side-effects of chemo and radiotherapy and prevention of recurrence, while CAM experts could, most of the time, hardly set any specific target, apart from the improvement of the quality of life of patients to different extents [10] [11].

In our Institute of Chinese Medicine, in the past years, we have conducted a number of clinical trials to investigate the potential use of Traditional Chinese medicine for cancer patients, summarized as follows:

a) Herbal formula to supplement chemotherapy as an agent to reduce toxicity [12];

b) Two herbs to reduce radiation symptoms [13];

c) Fungal supplement (Coriolus) to improve quality of life in breast cancer patients [14];

d) Fungal supplement (Coriolus) as preventive agent for immunological support [15]; and

e) Herbal formula to prevent bone metastasis [16].

As a matter of fact, Japan and Korea have a strong history of utilization of herbal formulae from China. Kampo in Japan, are ancient herbal formulae from China, used widely in hospitals for gastrointestinal problems during and after cancer treatment [17] [18]. Korean clinicians are sharing the same experience in their "Oriental Medicine" [19]. Cheng from Yale University of USA, has been working on a simple four herbs formula for the treatment of diarrhea resulting from chemotherapy [20].

We are aware of the fact that special medicinal herbs could be identified in the pursue of single molecule cytotoxic or target orientated agents in the Drug Discovery arena. As a matter of fact we are collaborating with other botanical institutes in specific explorations [21] [22] [23]. Nevertheless, we are more aware of the complicated situation of cancer pathology which might benefit from a holis- 
tic, multi-target approach as much as aiming at one specific target. The traditional practice of herbal supplements could have a lot to offer. The herbs that have been used for cancer related treatment are so plentiful that a proper literature search must be done in order to identify those that have proven effects and those that possess laboratory research data about their biological effects against cancer.

\section{Research to Justify the Use of Traditional Chinese Medicine for Cancer Patients}

Although modern pharmacology has plenty of examples of cytotoxic drugs related to botanical origins, the search for novel cancer therapy should out-reach to other areas related to cancer control, viz., cellular growth (apoptosis), restricting blood supply, immunological support and metastatic prevention.

Indeed many commonly used herbs have been found to possess those biological effects. Using them in a combined formula would have a multi-target effect which fits quite well into the classical theory of multi-target therapy advocated in the holistic treatment principle of CAM [21].

An active research program being conducted in Hong Kong is making use of five herbs, expected to form a synergistic combination to supplement conventional cancer treatment to give the following effects: apoptosis of cancer cells, anti-angiogenic effects, immunological suppression to cancer growth and prevention of metastasis.

The five herbs: Scutellaria; Hedyotis diffusa; Acanthopanax senticosus; Ganoderma lucidum and Andrographis paniculata, command excellent therapeutic records pertaining to what are required, (Table 1) and subsequent laboratory studies have added supportive information, on their varieties of anti-cancer activities, from cellular control, anti-angiogenesis to immune-modulations.

\section{Metronomic Chemotherapy}

After decades of development, cancer therapy has made remarkable advances. The current stage is one of keeping the combination of surgery, chemotherapy

Table 1. Traditional Use and Biological Properties of the Selected Herbs.

\begin{tabular}{|c|c|c|}
\hline & Traditional Use & Biological Properties \\
\hline \multirow{3}{*}{ Scutellaria } & Damp heat removal; & Anti-oxidation \\
\hline & Detoxicate & Anti-inflammation [22] \\
\hline & & Apoptosis \\
\hline \multirow[t]{2}{*}{ Hedyotis diffusa } & Heat removal, detoxicate & Immunomodulation \\
\hline & & Anti-angiogenesis [23] \\
\hline \multirow{2}{*}{$\begin{array}{c}\text { Acanthopanax } \\
\text { senticosus }\end{array}$} & \multirow{2}{*}{ Strengthening, Anti-aging } & Apoptosis \\
\hline & & Immunomodulation [24] \\
\hline \multirow{3}{*}{$\begin{array}{l}\text { Ganoderma } \\
\text { lucidum }\end{array}$} & \multirow{3}{*}{ Anti-aging } & Apoptosis \\
\hline & & Immunomodulation \\
\hline & & Anti-angiogenesis [25] [26] [27] \\
\hline \multirow{3}{*}{$\begin{array}{l}\text { Andrographis } \\
\text { paniculata }\end{array}$} & \multirow{3}{*}{ Strengthening } & Apoptosis \\
\hline & & Immunomodulation \\
\hline & & Anti-metastases [28] \\
\hline
\end{tabular}


and radiotherapy, while accepting new approaches of selective indications relying on genomic and proteomic identifications [29]. The improving outcomes however are related to mounting costs and yet refractory cases are still found. In developing districts, new forms of therapy are simply not affordable to most people [30] [31].

The outcome of the sad reality is the humanitarian use of cheap oral drugs with known low toxicity, particularly in low doses, in order to maintain survival. When the outcome appeared unusually satisfactory, clinicians started to explore the reasons of the unexpected outcome [32] [33].

Accumulated information from a large number of trials using metronomic, $1 / 3$ to $1 / 10$ oral doses revealed that survival and good quality of life were related to suppressed haemangiomatosis, immunological adjustment, slowing down of cellular promulgation and metastasis. Adverse effects had been mild because of low, oral dosages [34].

This appears a great practical achievement. The Metronomics Global Health Initiative henceforth is organized, to make better known the changing paradigm of cancer therapy. The conventional belief that cytotoxic therapy should be pushed to the utmost tolerable limit to ensure eradication is under challenge. At least for the refractory and late cases, the metronomic treatment protocol should have a place. And the results could be good [35] [36].

Since 2000, different cancer patients had been given metronomic chemotherapy. The varieties ranged from cancers of breast, liver, prostate and lung, to colorectal, pancreas and ovaries. Results had been mixed, with many favourable observations and survivals [37]-[45].

\section{Herbal Medicine and Metronomic Cancer Treatment}

The success of Metronomic Cancer Therapy has offered new insight into the multi-target approach. The good survivals and maintenance of good quality of life have indicated that the combined effects of cellular and angiogenic suppression, together with immunological adjustments, have helped maintain a balanced physiological well-being, very much like what CAM claims.

More importantly, the Metronomic cancer therapy has offered an excellent opportunity for a herbal regimen that can be proven to offer the same cancer control effects, viz., cellular and angiogenic control as well as immunological adjustment [46] Table 2 .

When the carefully selected herbal formula is added to the metronomic cancer treatment on a course of prolonged treatment, the logical outcome would be a significant enhancement of efficacy.

Before any clinical applicant, some early laboratory explorations have offered early support to the combined use of metronomic anticancer drug and herbal supplement.

\subsection{Metronomic Zoledronic Acid and Camellia Sinensis Extract in A Cancer Rat Model}

Zoledronic acid has been used as an anti-metastatic agent for breast cancer 
Table 2. Comparable Treatment Principles of Metronomic and Herbal Therapy.

\begin{tabular}{cc}
\hline Metronomic Treatment & Herbal Medicine Formula \\
\hline Low dose $1 / 3-1 / 10$ & Slow action \\
Frequent-Continuous & Frequent-Continuous \\
Multi-targets & Multi-targets \\
Haemangiostasis controls endothelial cell & Antiangiogenesis \\
Immunological adjustment & Immunological \\
Maintenance/Prevention & Prevention/Maintenance \\
Oral & Oral \\
Side effects low & Side effects low \\
\hline
\end{tabular}

patients [47] [48]. Camellia sinensis has been studied and proven positive in laboratories to be anti-angiogenic and anti-cancer [49] [50]. When zoledronic acid and camellia extracts were used together, they were found to inhibit cancer cell growth in-vitro and in-vivo, preventing bone metastasis. Notably a metronomic dose of zoledronic acid together with camellia extract, gave the most effective results [51].

\subsection{Immunohistochemical and Angiogenic Marker (VEGF) Changes Using Zoledronic Acid and Coriolus}

Coriolus is a popular immune-modulating agent of fungal origin popular among the cancer patients [52] [53]. It was explored on synergistic effects when used jointly with zoledronic acid, in ordinary and metronomic doses. In-vitro experiments were targeted on MMP2 and MMP9, control of which indicated efficacy on suppression of metastatic activities. A metronomic dose of zoledronic acid together with coriolus extract gave the best results [54]. VEGF was also suppressed in another in-vivo exploration [55].

\section{Discussion}

Chemotherapy has enjoyed 70 years of application during which many concepts, like Maximum Tolerable Dose (MTD); combination regimens and more recently "dose-dense administrations", have been applied in treatment protocols. High doses did optimize cancer cell destruction. However, the "more is better" approach may mask some of the subtle effects of chemotherapy against angiogenesis [56].

Laboratory studies have revealed that slow, continuous provision of anticancer therapy might bring out the anti-angiogenic effects better, which might relieve the need for MTD. The most convincing and demonstrable effects of metronomic therapy exist in the suppression of endothelial progenitor cells [33] [34]. The slowly rising trend of not totally relying on MTD is not only related to the threat against adverse effects but because of the early observations of good results from low dose and metronomic doses for different types of cancers, and the other evidences of immunological adjustments and cellular activities favouring 
metronomic therapy [35] [36].

Although cancer patients, under difficult situations of adverse effects during treatment or recurrences, do look for alternative medicine as supplementary therapy or replacement, specific indications about different herbs are just obscure, which cancer has been reported that to be cured by Traditional Chinese Medicine is equally uncertain. Afterall the main active chemical constituents of a traditional Chinese herb could be known. But whether this component is mainly responsible for cancer therapy could be equally uncertain. Hence, in the foreseeable future, medicinal herbs will continue to be utilized arbitrarily according to available reports and biological activity studies as adjuvant, or supplementary therapy, particularly for the refractory and late cases.

On the other hand, the low dose regimens are particularly inviting for the refractory cases and late presentations. Failed cancer eradication (referring to those resistant to treatment, those that are only partially controlled, recurrent, or actively metastatic) would be the most suitable to be enlisted for metronomic therapy [57].

Given the rising importance of metronomic treatment, herbal medicine which offers its anti-cancer support via exactly the same pathways of antiangiogenesis, immunological adjustments, control of cellular viability and metastasis, is being offered a wonderful opportunity to give innovative supports.

\section{Acknowledgements}

This study was supported by Grants on the State Key Laboratory of Phytochemistry and Plant Resources in West China (CUHK) form Hong Kong Special Administrative Region and the Chinese University of Hong Kong.

\section{References}

[1] Ferlay, J., Shin, H.R., Bray, F., Forman, D., Mathers, C. and Parkin, D.M. (2010) Estimates of Worldwide Burden of Caner in 2008: GLOBOCAN 2008. International Journal of Cancer, 127, 2893-2917.

[2] (2014) Hong Kong Cancer Registry, “Hong Kong Cancer Statistics 2014”. Hong Kong Hospital Authority, Hong Kong.

https://www3.ha.org.hk/cancereg/pdf/overview/Summary\%20of\%20CanStat\%20201 $\underline{4 . p d f}$

[3] Wang, X.S., Di, L.J., Reyes-Gibby, C.C., Guo, H., Liu, S.J. and Gleeland, C.S. (2004) End-of-Life Care in Urban Areas of China: A Survey of 60 Oncology Clinicians. Journal of Pain and Symptom Management, 27, 125-132. https://doi.org/10.1016/j.jpainsymman.2003.06.002

[4] Chen, K., Wang, P.P., Sun, B., Li, Q., Perruccio, A., Power, D., et al. (2006) Twenty-Year Secular Changes in Sex Specific Lung Cancer Incidence Rates in an Urban Chinese Population. Lung Cancer, 51, 13-19. https://doi.org/10.1016/j.lungcan.2005.08.013

[5] Andre, N. (2012) Metronomic Chemotherapy in Pediatric Oncology: A Way for Low-Income Countries? Metronomics Global Health Initiative. http://metronomics.newethicalbusiness.org/Metronomic-Chemotherapy-in,184

[6] Ernst, E. and Cassileth, B.R. (1998) The Prevalence of Complementary/Alternative 
Medicine in Cancer: A Systematic Review. Cancer, 83, 777-782. https://doi.org/10.1002/(SICI)1097-0142(19980815)83:4<777::AID-CNCR22>3.0.C $\underline{\mathrm{O} ; 2-\mathrm{O}}$

[7] Huebner, J., Prott, F.J., Micke, O., Muecke, R., Senf, B., Dennert, G., et al. (2014) Online Survey of Cancer Patients on Complementary and Alternative Medicine. Oncology Research and Treatment, 37, 304-308. https://doi.org/10.1159/000362616

[8] Deng, G. and Cassileth, B.R. (2005) Integrative Oncology: Complementary Therapies for Pain, Anxiety, and Mood Disturbance. CA: A Cancer Journal for Clinicians, 55, 109-116. https://doi.org/10.3322/canjclin.55.2.109

[9] Wong, T.W., Wong, S.L. and Sturat, P.B.D. (1993) Traditional Chinese Medicine and Western Medicine in Hong Kong: A Comparison of the Consultation Processes and Side Effects. Journal of Hong Kong Medical Association, 45, 278-284.

[10] Luo, J. and Chu, D.T. (2002) Evaluation of the Quality of Life in the Treatment of Malignant Tumor. Chinese Journal of Oncology, 24, 411-413.

[11] Schipper, H., Clinch, J., McMurray, A. and Levitt, M. (1984) Measuring the Quality of Life of Cancer Patients: The Functional Living Index-Cancer: Development and Validation. Journal of Clinical Oncology, 2, 472-483.

[12] Mok, T.S.K., Yeo, W., Johnson, P.J., Hui, P., Ho, W.M., Lam, K.C., et al. (2007) A Double-Blind Placebo-Controlled Randomized Study of Chinese Herbal Medicine as Complementary Therapy for Reduction of Chemotherapy-Induced Toxicity. Annals of Oncology, 18, 768-774. https://doi.org/10.1093/annonc/mdl465

[13] Bao, Y.X., Wong, C.K., Leung, S.F., Chan, A.T., Li, P.W., Wong, E.L., et al. (2006) Clinical Studies of Immunomodulatory Activities of Yunzhi-Danshen in Patients with Nasopharyngeal Carcinoma. Journal of Alternative and Complementary Medicine, 12, 771-776. https://doi.org/10.1089/acm.2006.12.771

[14] Wong, C.K., Bao, Y.X., Wong, E.L., Leung, P.C., Fung, K.P. and Lam, C.W. (2005) Immunomodulatory Activities of Yunzhi and Danshen in Post-Treatment Breast Cancer Patients. The American Journal of Chinese Medicine, 33, 381-395. https://doi.org/10.1142/S0192415X05002990

[15] Wong, C.K., Tse, P.S., Wong, E.L., Leung, P.C., Fung, K.P. and Lam, C.W. (2004) Immunomodulatory Effects of Yunzhi and Danshen Capsules in Health Subjects-A Randomized, Double-Blind, Placebo-Controlled, Crossover Study. International Immunopharmacology, 4, 201-211. https://doi.org/10.1016/j.intimp.2003.12.003

[16] Leung, P.C., Ooi, V., Wong, E.L.Y., Au, W.C., Wong, C.K., Lam, W.K., et al. (2007) Chinese Medicine and Cancer Treatment in Hong Kong. A General Review. Asia Pacific Biotech News, 11, 1108-1112.

http://www.asiabiotech.com/publication/apbn/11/english/preserved-docs/1116/110 8_1113.pdf https://doi.org/10.1142/9789812709301_0003

[17] Nikkei Medical Group (2007) Utilization Survey of Kampo Medicines. Vol. 10, 4147.

[18] Kono, T., Kanematsu, T. and Kitajima, M. (2009) Exodus of Kampo, Traditional Japanese Medicine, from the Complementary and Alternative Medicine: Is It Time Yet? Surgery, 146, 837-840. https://doi.org/10.1016/j.surg.2009.06.012

[19] Zhang, Q.H. and Leung, P.C. (2015) Practice and Research on Chinese Medicine Outside of China. In: Leung, P.C. Ed., A Comprehensive Guide to Chinese Medicine, World Scientific Publisher, Singapore, 209-238. https://doi.org/10.1142/9789814667081_0008

[20] Kummar, S., Copur, M.S., Rose, M., Wadler, S., Stephenson, J., O’Rourke, M., et al. 
(2011) A Phase I Study of the Chinese Herbal Medicine PHY906 as a Modulator of Irinotecan-Based Chemotherapy in Patients with Advanced Colorectal Cancer. Clinical Colorectal Cancer, 10, 85-96. https://doi.org/10.1016/j.clcc.2011.03.003

[21] Lau, C.B.S., Yue, G.G.L., Fung, K.P., Tan, N.H. and Leung, P.C. (2015) The Potential Role of Chinese Herbal Medicines in Cancer Management. Science, 347, S45S47.

[22] Chung, H.L., Yue, G.G.L., To, K.F., Su, Y.L., Huang, Y. and Ko, W.H. (2007) Effect of Scutellariae Radix Extract on Experimental Dextran-Sulfate Sodium-Induced Colitis in Rats. World Journal of Gastroenterology, 13, 5605-5611.

[23] Yue, G.G.L., Lee, J.K.M., Kowk, H.F., Cheng, L., Wong, E.C.W., Jiang, L., et al. (2015) Novel PI3K/AKT Targeting Anti-Angiogenic Activities of 4-Vinylphenol, a New Therapeutic Potential of a Well-Known Styrene Metabolite. Scientific Reports, 5, Article No. 11149. https://doi.org/10.1038/srep11149

[24] Hibasami, H., Fujikawa, T., Takeda, H., Nishibe, S., Satoh, T., Fujisawa, T., et al. (2000) Induction of Apoptosis by Acanthopanax senticosus HARMS and Its Component, Sesamin in Human Stomach Cancer KATO III Cells. Oncology Reports, 7, 1213-1216.

[25] Yue, G.G., Fung, K.P., Tse, G.M., Leung, P.C. and Lau, C.B. (2006) Comparative Studies of Various Ganoderma Species and Their Different Parts with Regards to Their Antitumor and Immunomodulating Activities in Vitro. Journal of Alternative and Complementary Medicine, 12, 777-789. https://doi.org/10.1089/acm.2006.12.777

[26] Yue, G.G., Fung, K.P., Leung, P.C. and Lau, C.B. (2008) Comparative Studies on the Immunomodulatory and Antitumor Activities of the Different Parts of Fruiting Body of Ganoderma lucidum and Ganoderma Spores. Phytotherapy Research, 22, 1282-1291. https://doi.org/10.1002/ptr.2478

[27] Han, X.Q., Yue, G.L., Yue, R.Q., Dong, C.X., Chan, C.L., Ko, C.H., et al. (2014) Structure Elucidation and Immunomodulatory Activities of a Beta Glucan from the Fruiting Bodies of Ganoderma sinense. PLoS ONE, 9, e100380. https://doi.org/10.1371/journal.pone.0100380

[28] Yue, G.G.L., Lee, J.K.M., Li, L., Chan, K.M., Wong, E.C.W., Chan, J.Y.W., et al. (2015) Andrographis paniculata Elicits Anti-Invasion Activities by Suppressing TM4SF3 Gene Expression and by Anoikis-Sensitization in Esophageal Cancer Cells. American Journal of Cancer Research, 5, 3570-3587.

[29] Meropol, N.J., Schrag, D., Smith, T.J., Mulvey, T.M., Langdon, R.M., Blum, D., et al. (2009) American Society of Clinical Oncology Guidance Statement: The Cost of Cancer Care. Journal of Clinical Oncology, 27, 3868-3874.

https://doi.org/10.1200/JCO.2009.23.1183

[30] Hanahan, D., Bergers, G. and Bergsland, E. (2000) Less Is More, Regularly: Metronomic Dosing of Cytotoxic Drugs Can Target Tumor Angiogenesis in Mice. Journal of Clinical Investigation, 108, 1045-1047. https://doi.org/10.1172/JCI9872

[31] Goss, P.E., Strasser-Weippl, K., Lee-Bychkovsky, B.L., Fan, L., Li, J., Chavarri-Guerra, Y., et al. (2014) Challenges to Effective Cancer Control in China, India and Russia. The Lancet Oncology, 15, 489-538.

https://doi.org/10.1016/S1470-2045(14)70029-4

[32] Andre, N., Banavali, S., Snihur, Y. and Pasquier, E. (2013) Has the Time Come for Metronomics in Low-Income and Middle-Income Countries? The Lancet Oncology, 14, e239-e248.

[33] Kerbel, R.S. and Kamen, B.A. (2004) The Anti-Angiogenic Basic of Metronomic Chemotherapy. Nature Reviews Cancer, 4, 423-436. https://doi.org/10.1038/nrc1369 
[34] Shaked, Y., Emmenegger, U., Man, S., Cervi, D., Bertolini, F., Ben-David, Y., et al. (2005) Optimal Biologic Dose of Metronomic Chemotherapy Regimens Is Associated with Maximum Anti-Angiogenic Activity. Blood, 106, 3058-3061. https://doi.org/10.1182/blood-2005-04-1422

[35] Scharovsky, O.G., Mainetti, L.E. and Rozados, V.R. (2009) Metronomic Chemotherapy: Changing the Paradigm That More Is Better. Current Oncology, 16, 7-15. https://doi.org/10.3747/co.v16i2.420

[36] Maiti, R. (2014) Metronomic Chemotherapy. Journal of Pharmacology and Pharmacotherapeutics, 5, 186-192. https://doi.org/10.4103/0976-500X.136098

[37] Mross, K. and Steinbild, S. (2012) Metronomic Anti-Cancer Therapy-An Ongoing Treatment Option for Advanced Cancer Patients. Journal of Cancer Therapeutics and Research, 1, 32. https://doi.org/10.7243/2049-7962-1-32

[38] Collova, E., Sebastiani, F., De Matteis, E., Generali, D., Aurillio, G., Boccardo, F., et al. (2011) Use of Metronomic Chemotherapy in Oncology: Results from a National Italian Survey. Tumori Journal, 97, 454-458.

[39] Bocci, G., Tuccori, M., Emmenegger, U., Liquori, V., Falcone, A., Kerbel, R.S., et al. (2005) Cyclophosphamide-Methotrexate Metronomic Chemotherapy for the Palliative Treatment of Metastatic Breast Cancer. A Comparative Pharmacoeconomic Evaluation. Annals of Oncology, 16, 1243-1252.

https://doi.org/10.1093/annonc/mdi240

[40] Kato, H., Ichinose, Y., Ohta, M., Hata, E., Tsubota, N., Tada, H., et al. (2004) A Randomized Trial of Adjuvant Chemotherapy with Uracil-Tegafur for Adenocarcinoma of the Lung. The New England Journal of Medicine, 350, 1713-1721. https://doi.org/10.1056/NEJMoa032792

[41] Martin-Padura, I., Marighetti, P., Agliano, A., Colombo, F., Larzabal, L., Redrado, M., et al. (2012) Residual Dormant Cancer Stem-Cell Foci Are Responsible for Tumor Relapse after Antiangiogenic Metronomic Therapy in Hepatocellular Carcinoma Xenografts. Laboratory Investigation, 92, 952-966. https://doi.org/10.1038/labinvest.2012.65

[42] Emmenegger, U., Francia, G., Shaked, Y. and Kerbel, R.S. (2010) Metronomic Chemotherapy: Principles and Lessons Learned from Applications in the Treatment of Metastatic Prostate Cancer. Recent Results in Cancer Research, 180, 165-183. https://doi.org/10.1007/978-3-540-78281-0_10

[43] Kamen, B.A. (2005) Metronomic Therapy: It Makes Sense and Is Patient Friendly. Journal of Pediatric Hematology/ Oncology, 27, 571-572. https://doi.org/10.1097/01.mph.0000192148.90120.15

[44] Sobrero, A.F., Aschele, C. and Bertino, J.R. (1997) Fluorouracil in Colorectal Cancer-A Tale of Two Drugs: Implications for Biochemical Modulation. Journal of Clinical Oncology, 15, 368-381.

[45] Takahashi, Y., Mai, M., Sawabu, N. and Nishioka, K. (2005) A Pilot Study of Individualized Maximum Repeatable Dose (iMRD), a New Dose Finding System, of Weekly Gemcitabine for Patients with Metastatic Pancreas Cancer. Pancreas, 30, 206-210. https://doi.org/10.1097/01.mpa.0000153335.73352.c7

[46] Pasquier, E., Kavallaris, M. and Andre, N. (2010) Metromic Chemotherapy: New Rationale for New Directions. Nature Reviews Clinical Oncology, 7, 455-465. https://doi.org/10.1038/nrclinonc.2010.82

[47] Labrinidis, A., Hay, S., Lipis, V., Findlay, D.M. and Evdokiou, A. (2010) Zoledronic Acid Protects Against Osteosarcoma-Induced Bone Destruction but Lacks Efficacy against Pulmonary Metastases in a Syngeneic Rat Model. International Journal of Cancer, 127, 345-354. https://doi.org/10.1002/ijc.25051 
[48] Ottewell, P.D., Woodward, J.K., Lefley, D.V., Evans, C.A., Coleman, R.E. and Holen, I. (2009) Anticancer Mechanisms of Doxorubicin and Zoledronic Acid in Breast Cancer Tumor Growth in Bone. Molecular Cancer Therapeutics, 8, 28212832. https://doi.org/10.1158/1535-7163.MCT-09-0462

[49] Thangapazham, R.L., Passi, N. and Maheshwari, R.K. (2007) Green Tea Polyphenol and Epigallocatechin Gallate Induce Apoptosis and Inhibit Invasion in Human Breast Cancer Cells. Cancer Biology \& Therapy, 6, 1938-1943.

https://doi.org/10.4161/cbt.6.12.4974

[50] Luo, K.W., Ko, C.H., Yue, G.G., Lee, J.K., Li, K.K., Lee, M., et al. (2014) Green Tea (Camellia sinensis) Extract Inhibits Both the Metastasis and Osteolytic Components of Mammary Cancer 4T1 Lesions in Mice. The Journal of Nutritional Biochemistry, 25, 395-403. https://doi.org/10.1016/j.jnutbio.2013.11.013

[51] Luo, K.W., Ko, C.H., Yue, G.G., Gao, S., Lee, J.K., Li, G., et al. (2015) The Combined Use of Camellia sinensis and Metronomic Zoledronic Acid in a Breast Cancer-Induced Osteolysis Mouse Model. Journal of Cancer Research and Clinical Oncology, 141, 1025-1036. https://doi.org/10.1007/s00432-014-1882-1

[52] Luo, K.W., Yue, G.G., Ko, C.H., Lee, J.K., Gao, S., Li, L.F., et al. (2014) In Vivo and in Vitro Anti-Tumor and Anti-Metastasis Effects of Coriolus Versicolor Aqueous Extract on Mouse Mammary 4T1 Carcinoma. Phytomedicine, 21, 1078-1087. https://doi.org/10.1016/j.phymed.2014.04.020

[53] Wong, E., Cheng, K.F. and Leung, P.C. (2012) Efficacy of Yunzhi (Trametes versicolor) on Survival in Cancer Patients: Systematic Review and Meta-Analysis. Recent Patents on Inflammation \& Allergy Drug Discovery, 6, 78-87. https://doi.org/10.2174/187221312798889310

[54] Luo, K.W., Ko, C.H., Yue, G.G., Lee, M.Y., Siu, W.S., Lee, J.K., et al. (2013) Anti-Tumor and Anti-Osteolysis Effects of the Metronomic Use of Zoledronic Acid in Primary and Metastatic Breast Cancer Mouse Models. Cancer Letters, 339, 42-48. https://doi.org/10.1016/j.canlet.2013.07.024

[55] Zhao, X., Xu, X., Guo, L., Ragaz, J, Guo, H., Wu, J., et al. (2010) Biomarker Alterations with Metronomic Use of Low-Dose Zoledronic Acid for Breast Cancer Patients with Bone Metastases and Potential Clinical Significance. Breast Cancer Res Treat, 124, 733-743. https://doi.org/10.1007/s10549-010-1183-6

[56] Lien, K., Georgsdottir, S., Sivanathan, L., Chan, K. and Emmenegger, U. (2013) Low-Dose Metronomic Chemotherapy: A Systematic Literature Analysis. European Journal of Cancer, 49, 3387-3395. https://doi.org/10.1016/j.ejca.2013.06.038

[57] Noronha, V., Krishna, M.V., Patil, V., Joshi, A., Banavali, S.D. and Prabhash, K. (2013) Metronomic Therapy: Chemotherapy Revisited. Indian Journal of Cancer, 50, 142-148. https://doi.org/10.4103/0019-509X.117027 
Submit or recommend next manuscript to SCIRP and we will provide best service for you:

Accepting pre-submission inquiries through Email, Facebook, LinkedIn, Twitter, etc. A wide selection of journals (inclusive of 9 subjects, more than 200 journals)

Providing 24-hour high-quality service

User-friendly online submission system

Fair and swift peer-review system

Efficient typesetting and proofreading procedure

Display of the result of downloads and visits, as well as the number of cited articles Maximum dissemination of your research work

Submit your manuscript at: http://papersubmission.scirp.org/

Or contact jet@scirp.org 